\title{
Study of Behaviour Dynamic of the Pedestrian Loading on a Footbridge
}

\author{
J. E. Cerón Carballo, I. Palma Quiroz, E. Pérez Isidro \\ Área Académica de Ingeniería y Arquitectura \\ Universidad Autónoma del Estado de Hidalgo \\ Mineral de la Reforma, Hidalgo, México
}

\author{
N. Sao Soto \\ Universidad Autónoma de Sonora. Hermosillo, \\ Sonora. Mexico
}

\begin{abstract}
This paper presents the study of the movement between a passerby and the concrete walkway of a type armor footbridge, located in the Pachuca de Soto, Hidalgo, Mexico. In which readings were taken people walking with a portable equipment. The human body modeled as a dynamic system consisting of a mass concentrated in its gravity center and two docks representing damped passage. The movement of the mass simulated in a scheme that consists vertical and lateral displacement representation in the footbridge. The influence of the wind or other type of dynamic excitation on the footbridge is not examined here. The scheme idealized in a mathematical model matrixed coupling with the motion equation, through Lagrangian mechanics. It considers the temporary movement of the mass, and the dynamic response of the catwalk. This displacement is the result obtained by the restoration of the concrete footbridge and the energy contribution of the model when walking of six proposed cases, corresponding to different frequencies of passage and human mass, obtaining values that help to identify that the structural performance of the bridge, maintains optimal service conditions.
\end{abstract}

Keywords - Pedestrian-loading, Dynamic, Footbridge, Lagrange-mechanics

\section{INTRODUCTION.}

The footbridge on the bridges has its own dynamic behavior, so it does not matter if this have long or short lights, or their elements are slender or robust, they will always be prone to vibrations, and as a consequence, the vibration service of these structures is a criterion of constant analysis[1]. Currently, the analysis procedures and control of vibrations, used in professional practice are increasingly demanding [2], This causes the research models more effective.

The social demands related to the structural security in these footbridges, they raise the need to develop adequate methodologies for analysis and an accurate design assisted by a computer, the authors propose to integrate experimental strategies, for to identify the relevant factors that intervene in the behavior structural. In the specific case in the footbridge, there are prone to be stimulated by the people who use them, appearing movements, which can even become annoying or, in some cases, unstable from the point of view of structural resistance [3].

Currently the people in movement in the footbridges, is a determining factor in the structural design, particularly in the face of vibrations, which are the product of the application of the force of the walk on the structure, this criterion has as its main parameter the step frequency $\left(f_{p}\right)$, contemplation of the characteristics of load in the structure, not properly to improve the behaviour in the face of an stimulation, but, result of the incorporation of the dynamics that people can provoke the structure. The inclusion of measuring this parameter in the dynamic load characteristics allows a more accurate response, considering that the excitation force continuously produces vibrations in this structures types [4].

A footbridge is a structure that can easily be represented by a beam with simple or continuous supports, in this case, the separation between the supports or light of the bridge represents a determining factor in the static characteristics (deflection, bending moments, cutting plane) and in the dynamic characteristics on this structure (maximum acceleration, vibration modes). The instruments that measure said acceleration, contains signal conditioners provided with filters, said filtered signal is transmitted by means of cables connected to a computer[5].

The corresponding limits for the acceleration and the frequency in a footbridge of a bridge, must satisfy the regulations, it is for this reason, that the authors investigate the capacity of service of the structure determining the levels of vibration (in terms of maximum acceleration) under induced excitations. The evaluation of the service capacity through experimental tests began with the appearance of the environmental vibration performed to obtain the modal characteristics of the catwalk. After the comparison of the experimental and numerical results, the dynamic response is evaluated both experimentally and analytically under different pedestrian excitations, taking individual, group, walking, or jumping characteristics[6].

The walking of pedestrians is a complex theme, random and stochastic, issue that is often coupling to sensitive dynamic systems with vertical and lateral movement [7], in addition, the contact forces included on the acceleration of the human body are by influenced by the lateral oscillation of the support structure [8]. On the other hand, the footsteps are often synchronized with lateral structural movement, and in doing so, apply energy within the dynamic system of the coupled human structure while acting as negative buffers in the vertical direction. The authors indicate that the walking mainly dampens vertical vibrations, because they present conclusive results with higher magnitudes[9]. To date, coupled models have been proposed to describe the behavior in the vertical direction. Adopted from the biomechanics of human gait, the model represented in a pedestrian as a simple inverted pendulum that 
oscillates in the vertical plane while moving along a bridge. That was first used by Macdonald, to simulate the interaction of the pedestrian and the structure, on bridges that swing laterally, then adapted by Bocian to describe the vertical vibration. In this study, and are identify mechanism was created whereby the time of successive footsteps can be subtly altered in a step-by-step manner. Their numerical simulations showed that a pedestrian acts as a positive or negative shock absorber to the vertical dynamic response, depending on the relationship between the frequency of vibration of the bridge and frequency of pedestrian stimulation[10].

\section{DYNAMIC SYSTEM OVERVIEW}

The formulation of the system contemplates the coupling of three models; the biped, the biomechanical and the mathematical, through the equations of movement, the mechanics of Lagrange and the measured displacements of the center of gravity of the pedestrian in motion[11].

The conditions of use and service of these structural systems currently, must comply with globalized standards[12], and therefore, must be applied the criteria necessary to meet the current design codes, in these conditions is essential to perform tests of vibration in the different constructed walkways, to detect experimentally the initiation of vibration problems, under the excitation of the different load combinations[13].

The evaluation of the service capacity of the constructed footbridges, suggest the authors, the unification of a load model that incorporates the frequencies of the different phenomena that produce accelerations that give rise to the initiation of a limit state of service or failure, for this reason, in this work we analyze the vibration that stimulates the walk of a pedestrian on a walkway of a type armature footbridge, where the structure is subjected to a dynamic system controlled according to the regulations established by current codes [14]

The basic mechanics that govern the present model, is determined by the essential form of walking, for this reason, human locomotion is associated with a dynamic representation of a mass-spring-damper system[25], since, when supporting the mass with the legs , they perform a function of rigidity and damping, then then, generates contact forces, which can vary with the kinematics of the center of mass during the entire cycle of the march, which makes note, the complicated of the analysis, incorporating multiple masses and buffer effects without being unified to a regulation criterion [15].

In the present work a bipedal model has been considered at a conceptual level, which is sufficiently realistic, therefore, studying the contact force in each moment to control and compensate the energy of contribution to the vibration, is a useful task, and its It is necessary, since, by knowing the periodic charge experimentally, which is exercised by walking, it determines the footbridge interaction [16].
The gangway is a rigid structure, which does not provide energy, when it is coupled to a flexible system, as is a structural steel armor of said bridge, so that the kinetic energy is acquired by the vibration due to the movement of the pedestrian.

On the other hand, this structure has elasticity and flexion of the structural continuity, in such a way that it constitutes a linear system in the elastic zone, subject to a forced excitation, and when the pedestrian model is coupled, it produces the conformation of the periodic load, which together, make the system linear semi-elastic, whose analysis techniques require advanced numerical solutions [17].

The work has been organized in the following manner: firstly, the methodology used in analytical and experimental form is presented, then the results obtained are presented and the conclusions that end this work are presented.

Once the above is done, the energy contribution of both the pedestrian and the entire system is known, thereby finding the magnitudes of the restoration displacements of the bridge footbridge under study, as it represents in the block diagram shown in the Figure 1.

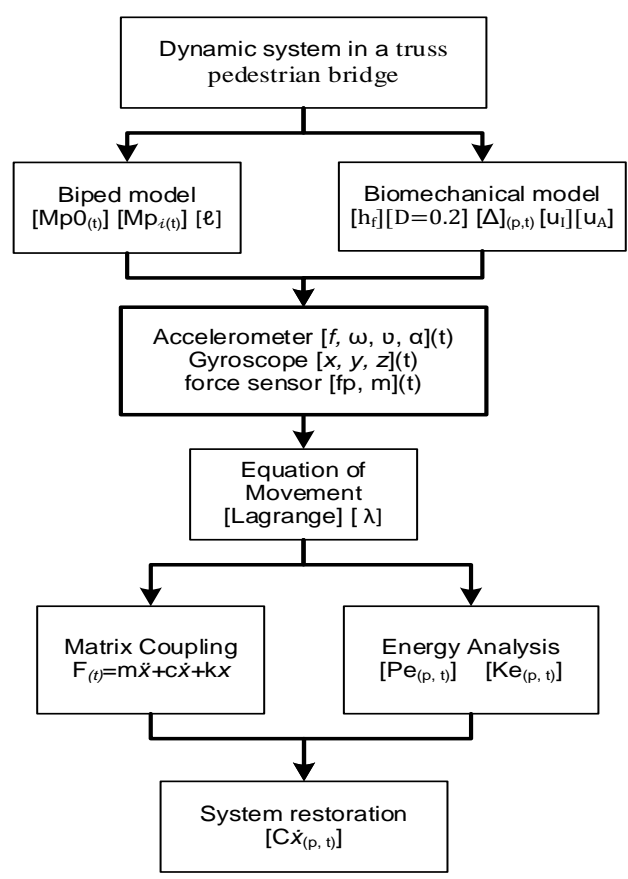

Fig. 1. Blocks diagram of the dynamic system of model in a truss footbridge

\section{A. Pedestrian-structure model.}

The simulation of the pedestrian in the bipedal model considers two degrees of freedom, as seen in Figure 2, the pedestrian is modeled considering a concentrated mass $\left(\mathrm{m}_{\mathrm{p}}\right)$, at the center of gravity $\left(\mathrm{C}_{\mathrm{g}}\right)$, and both legs are presented as two springs of stiffness $K_{p}$, while the step considers two periods: the impulse phase and the arrival phase. 


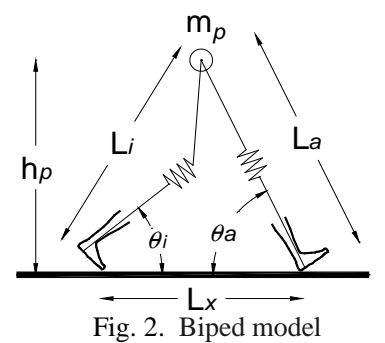

The force produced by walking has two analysis options that exercise periodic loading on the catwalk; the first is the impulse of the support foot and the second is the arrival of the other foot, this is where the acceleration occurs [18] (depending on the time), in three directions of the center of gravity $\left(\mathrm{u}_{\mathrm{x}}, \mathrm{u}_{\mathrm{y}}, \mathrm{u}_{\mathrm{z}}\right)_{(\mathrm{t})}$. As to show in Figure 3.

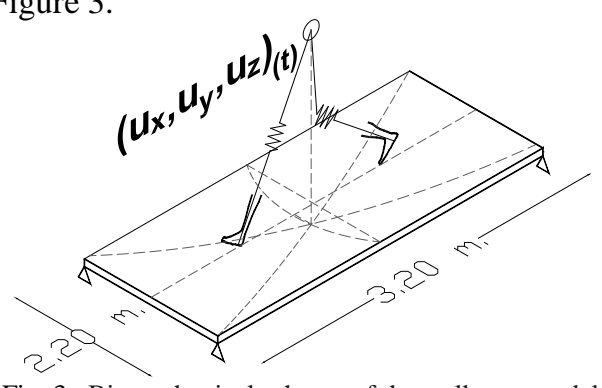

Fig. 3. Biomechanical scheme of the walkway model.

Figure 4 shows a lateral scheme of the model of walking, note the displacement of the legs that progresses from impulse to arrival $\left(\mathrm{u}_{\mathrm{xi}}, \mathrm{u}_{\mathrm{xa}}\right)_{(\mathrm{t})},\left(\mathrm{u}_{\mathrm{zi}}, \mathrm{u}_{\mathrm{za}}\right)_{(\mathrm{t})}$, likewise, we observe the displacement that has the $\mathrm{C}_{\mathrm{g}}\left(\mathrm{u}_{\mathrm{x}}, \mathrm{u}_{\mathrm{z}}\right)_{(\mathrm{t})}$, this defines the values captured experimentally, and responds to the questioning of the sign of the value captured from the instrumental.

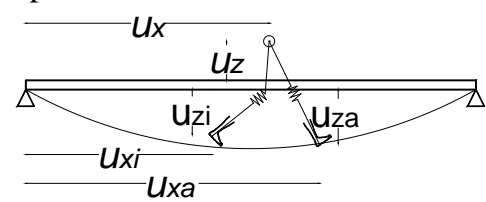

Fig. 4. Lateral diagram of the mathematical model of twodimensional dynamic analysis in the catwalk.

Figure 5 shows a frontal scheme of the model of walking, note the displacement of the legs that advances from impulse to arrival ( $\left.\mathrm{u}_{\mathrm{yi}}, \mathrm{u}_{\mathrm{ya}}\right)_{(\mathrm{t})},\left(\mathrm{u}_{\mathrm{zi}}, \mathrm{u}_{\mathrm{za}}\right)_{(\mathrm{t})}$, likewise, we observe the displacement that has the $\mathrm{C}_{\mathrm{g}}\left(\mathrm{u}_{\mathrm{y}}, \mathrm{u}_{\mathrm{z}}\right)_{(\mathrm{t}) \text {, }}$

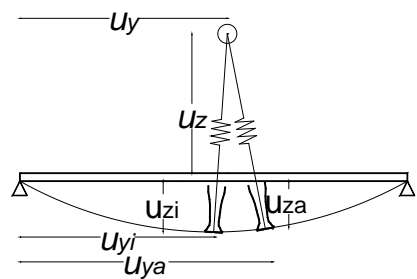

Fig. 5. Front diagram of the mathematical model of twodimensional dynamic analysis in the catwalk.

The structure of analysis considered for the present work, consists of a concrete slab supported perimetrally, as observed in the biomechanical scheme, in addition, where the greatest deflection is generated by the walk of the pedestrian, and is in the furthest part of the supports [19], therefore, the conditions of the structure under a forced excitation in lateral and frontal direction, shows a linear system whose temporal response is determined with digital instruments, placed in a portable way in the center of gravity of the pedestrian, represented in the form of a circle in the scheme of the model.

\section{B. Matrix coupling.}

It is assumed that the pedestrian maintains contact at all times with the surface of the footbridge of the bridge under study, as shown in Figure 3, likewise, it is assumed that the portable measurement equipment captures displacement data $\left(\mathrm{u}_{\mathrm{x}}, \mathrm{u}_{\mathrm{y}}, \mathrm{u}_{\mathrm{z}}\right.$ )$_{(t)}$ that has the center of gravity of the pedestrian when walking, the response that the sensor emits, as was done in [20], has a duration of $60 \mathrm{~s}$, time that is necessary to travel along the walkway, back and forth, since the average speed is less than $1.25 \mathrm{~m} / \mathrm{s}$, as in [20], and the length of the footbridge is $45.43 \mathrm{~m}$. On the other hand, the equations of motion governing the vibration [21] are represented by the Lagrange equation [22], where the kinetic energy $\left(E_{c}\right)$ and the potential energy $\left(E_{p}\right)$ of the temporary dynamic system of the pedestrian and structure are obtained from equation 1.

$$
\begin{aligned}
& \lambda=E c-E p
\end{aligned}
$$

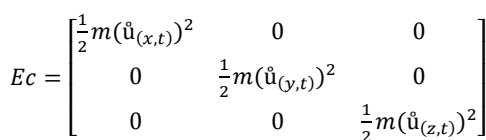

$$
\begin{aligned}
& E p_{1}=\left[\begin{array}{ccc}
\frac{1}{2} K\left(u_{(x, t)}\right)^{2} & 0 & 0 \\
0 & \frac{1}{2} K\left(u_{(y, t)}\right)^{2} & 0 \\
0 & 0 & \frac{1}{2} K\left(u_{(z, t)}\right)^{2}
\end{array}\right] \\
& E p_{2}=\left[\begin{array}{ccc}
m g h \cos \left(\theta_{(x, t)}\right) & 0 & 0 \\
0 & m g h \cos \left(\theta_{(y, t)}\right) & 0 \\
0 & 0 & m g h_{z}
\end{array}\right]
\end{aligned}
$$

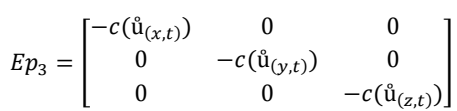

substituting 2, 3, 4, 5 in 1 ;

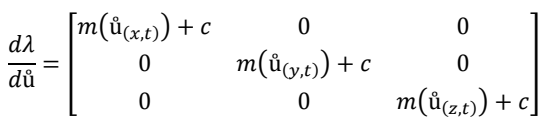

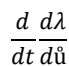

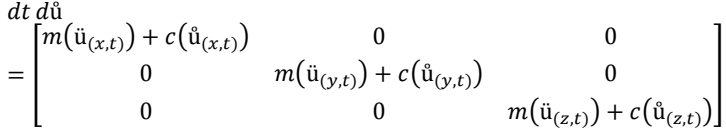

$$
\begin{aligned}
& \frac{d \lambda}{d u}=\left[\begin{array}{ccc}
-K\left(u_{(x, t)}\right) & 0 & 0 \\
0 & -K\left(u_{(y, t)}\right) & 0 \\
0 & 0 & -K\left(u_{(z, t)}\right)
\end{array}\right]
\end{aligned}
$$

De Lagrange:

$$
\begin{aligned}
& F_{(t)}=\frac{d}{d t} \frac{d \lambda}{d \grave{u}}-\frac{d \lambda}{d u}
\end{aligned}
$$

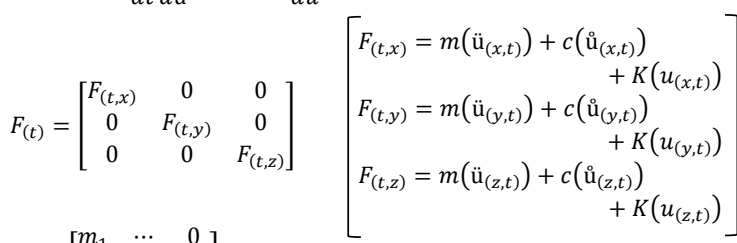

$$
\begin{aligned}
& M=\left[\begin{array}{ccc}
m_{1} & \cdots & 0 \\
\vdots & \ddots & \vdots \\
0 & \cdots & m_{6}
\end{array}\right] \\
& C=\left[\begin{array}{ccc}
2 \xi_{1} \omega_{1} m_{1} & \cdots & 0 \\
\vdots & \ddots & \vdots \\
0 & \cdots & 2 \xi_{6} \omega_{6} m_{6}
\end{array}\right] \\
& K=\left[\begin{array}{ccc}
\omega_{1}^{2} m_{1} & \cdots & 0 \\
\vdots & \ddots & \vdots \\
0 & \cdots & \omega_{6}^{2} m_{6}
\end{array}\right]
\end{aligned}
$$




\section{Energy contribution.}

The movement of the $\mathrm{C}_{\mathrm{g}}$ will have generalized coordinates, whose displacement will be in the direction $\left(\mathrm{u}_{\mathrm{x}}, \mathrm{u}_{\mathrm{y}}, \mathrm{u}_{\mathrm{z}}\right)_{(\mathrm{t})}$, horizontal and vertical, over time, due to the energy used to reproduce the walking gait in the footbridge, shown in the bipedal model, this energy, to maintain the cycle, yield energy to the slab of the footbridge, which is also partially dissipated by damping $\left(\delta_{\mathrm{x}}, \delta_{\mathrm{y}}, \delta_{\mathrm{z}}\right)(\mathrm{t})$, in addition, legs of the pedestrian have a stiffness $\left(K_{x}, K_{y}, K_{z}\right)_{(t)}$, and support the energy provide, transmitting it to the contact surface, the above, generates kinetic energy, which the pedestrian contributes to the system $\left[E_{c}(p, t)\right.$, Ep $(p, t)]$, and potential, both magnitudes are determined with equation 14 and 15 correspondingly.

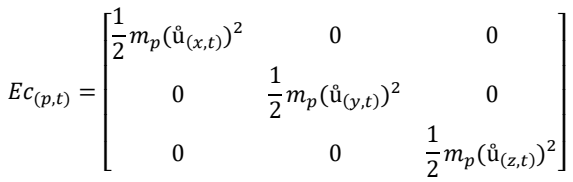

$$
\begin{aligned}
& E p_{(p, t)} \\
& =\left[\begin{array}{ccc}
E p_{(x, t)} & 0 & 0 \\
0 & E p_{(y, t)} & 0 \\
0 & 0 & E p_{(z, t)}
\end{array}\right] \\
& E p_{(x, t)}=\frac{1}{2} K_{p}\left(u_{(x, t)}\right)^{2}+m g h \cos \left(\theta_{(x, t)}\right) \\
& E p_{(y, t)}=\frac{1}{2} K_{p}\left(u_{(y, t)}\right)^{2}+m g h \cos \left(\theta_{(y, t)}\right) \\
& E p_{(y, t)}=\frac{1}{2} K_{p}\left(u_{(z, t)}\right)^{2}+m g h
\end{aligned}
$$

\section{Energy restoration of the system.}

It is assumed that the initial conditions of the system consider a coupling of the dynamic pedestrian model with the armor-type footbridge, maintaining at all times the measurement of the displacement of the $\mathrm{C}_{\mathrm{g}}$, and it is assumed that this represents the temporary position of the vector that reproduces all the effects, as observed in the scheme of the model of walking, used in [23], being in this way a dynamic system with energy dissipation in the contact structure. By means of the damping of the material $\left(C_{x}, C_{y}, C_{z}\right)(t)$, an imaginary curvature is generated in the slab, in such a way that the potential energy in the catwalk $\left(\operatorname{Epp}_{(\mathrm{x}, \mathrm{t})}\right)$, $\left(\operatorname{Epp}_{(y, t)}\right),\left(\operatorname{Epp}_{(\mathrm{z}, \mathrm{t})}\right)$, is integrate by the equations 16,17 and 18 , respectively.

$$
\begin{aligned}
& \operatorname{Epp}_{(x, t)}=\frac{1}{2} K p\left(u_{(x, t)}-u_{(x, 0)}\right)^{2}+m g h c o s\left(\theta_{(x, t)}\right) \\
& +\frac{1}{2} E I \int_{0}^{l x}\left(u^{\prime \prime}(x, t)\right)^{2} d x \\
& \operatorname{Epp}_{(y, t)}=\frac{1}{2} K p\left(u_{(y, t)}-u_{(y, 0)}\right)^{2}+m g h \cos \left(\theta_{(y, t)}\right) \\
& +\frac{1}{2} E I \int_{o}^{l y}\left(u^{\prime \prime}(y, t)\right)^{2} d y \\
& E p p_{(z, t)}=\frac{1}{2} K p\left(u_{(z, t)}-u_{(z, 0)}\right)^{2}+m g h+\frac{1}{2} E I \int_{0}^{l z}\left(u^{\prime \prime}(z, t)\right)^{2} d z
\end{aligned}
$$

\section{E. Energy analysis.}

To illustrate the model, the present study is on a concrete walkway supported perimetrally in primary and secondary steel structural beams, which form a flexible system, where the longitudinal torsion effect is despised.

It is assumed for the present analysis that the deformations with greater magnitude, are located in the center of the concrete slab of the footbridge, said board has $3.20 \mathrm{~m}$ in length, $2.20 \mathrm{~m}$ in width and $0.12 \mathrm{~m}$ in thickness.

The properties of the slab are: $E_{I}=6.840105 \mathrm{~N}^{*} \mathrm{~m}^{2}$, where $\mathrm{E}$ is the modulus of elasticity of concrete, obtained by measuring the resistance to compression with a manual sclerometer with digital display, using the equation: $E=14100 \sqrt[2]{f^{\prime} c}$, where $\mathrm{f}_{\mathrm{c}}$ is the average compressive strength, measured, determined from the data of ten samples (two samples in each of the three supports and two samples in each of the two clear centers), and I is the moment of inertia of the cross section in the footbridge, with an initial damping $\xi_{\mathrm{i}}=1.65 \%$ in a scenario of type 1 as in [24], likewise, the properties of the pedestrian are those shown in the table 1, determined according to [25].

Table 1. Characteristics of pedestrians

\begin{tabular}{|c|c|r|r|r|}
\hline No. & Sex & Size $[\mathrm{m}]$. & $\mathrm{W}_{\mathrm{p}}[\mathrm{N}]$. & $\mathrm{f}_{\mathrm{p}}[$ Step/s] \\
\hline 1 & Woman & 1.52 & 530 & 1.441 \\
\hline 2 & Woman & 1.55 & 569 & 1.412 \\
\hline 3 & Woman & 1.61 & 608 & 1.441 \\
\hline 4 & Man & 1.71 & 755 & 1.382 \\
\hline 5 & Man & 1.74 & 804 & 1.529 \\
\hline 6 & Man & 1.80 & 942 & 1.706 \\
\hline
\end{tabular}

The periodic load [19] was determined with the pressure cell located on the sole of the foot of the pedestrian, in a portable way, in the same way data of the acceleration of the mass is obtained, with an accelerometer and portable gyroscope, located in the center of gravity of the pedestrian, the data of the pressure cell are represented graphically in the Figure 6.

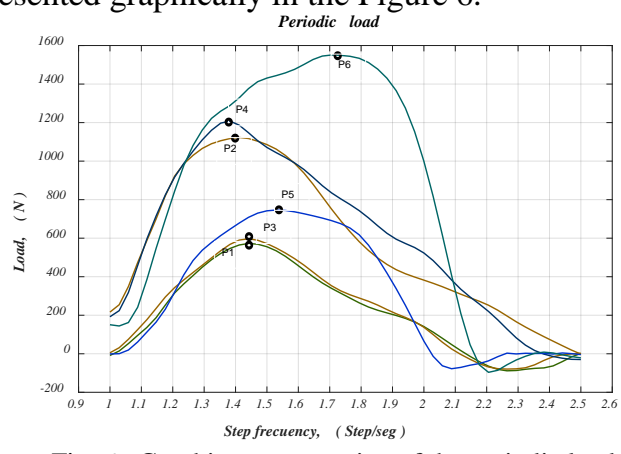

Fig. 6. Graphic representation of the periodic load

\section{ANALYTICAL PROCESS.}

Each pedestrian walks on the same footbridge at an individual step frequency $\left(f_{p}\right)$, which causes the mass to exert a force that is transmitted to the contact surface as shown in Figure 6 , based on this information, when applying the method of double integration [26], it's found the expected displacement of the footbridge, which is represented in the Figure 7.

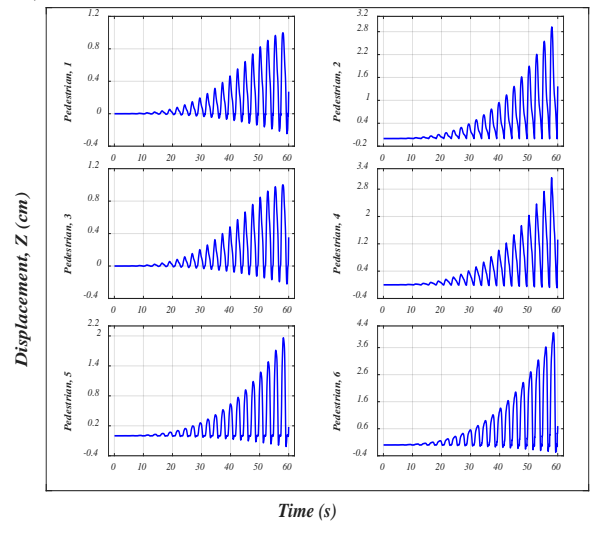

Fig. 7. Graphic representation of the Displacement on the catwalk caused by periodic loading.

The graphic representation of Figure 8 shows similarity in the cyclic form as determined in [13]. The magnitude of the load applied in the direction $(x, y, z)$ allows us to observe a correlation with the periodic load, this finding being more noticeable in the vertical direction. Whose continuity remains throughout timehistory, in such a way that the mass of the pedestrian becomes part of the system, when its load changes sign, and is coupled to 
the displacement of the mass of the footbridge, this means that the pedestrian it is part of the system instantaneously in each of the three directions at different times and periods, in the same way at another time it is excluded from the bridge.

\section{A. Numerical simulation.}

In the present work two load magnitudes are considered, which are analyzed independently; the periodic load, measured instrumentally represented in Figure 6 and, the load produced by the movement of the mass in the time domain, Figure 8.
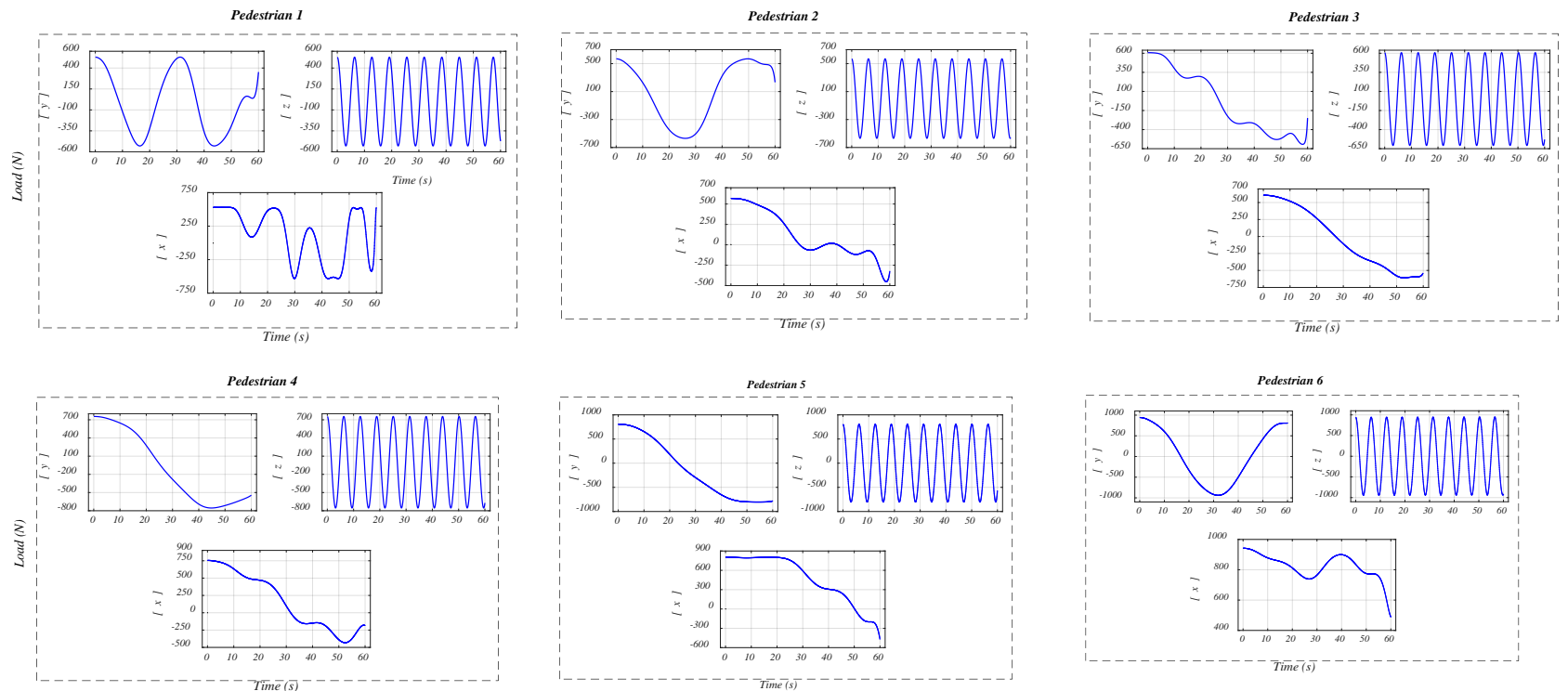

Fig. 8. Graphic representation of the Cyclic loading patterns

The evolution of the load over time in the direction $(x, y, z)$, is represented in Figure 8, where the six pedestrians walk individually through the footbridge of the bridge in study, applying force as indicated in the equation $F_{(p, t)}=A \cos (\omega \tau)$, applying this time series as in [2], we obtain a pattern in the behavior of the vertical force, and lateral, applying the frontal and lateral scheme of the pedestrian model, assuming that the amplitude in all the cases is the value of the mass $\left(\mathrm{W}_{\mathrm{p}}\right)$, and, the temporal domain that corresponds to the measured readings of the speed that the instrument during measured over 60 seconds of history.
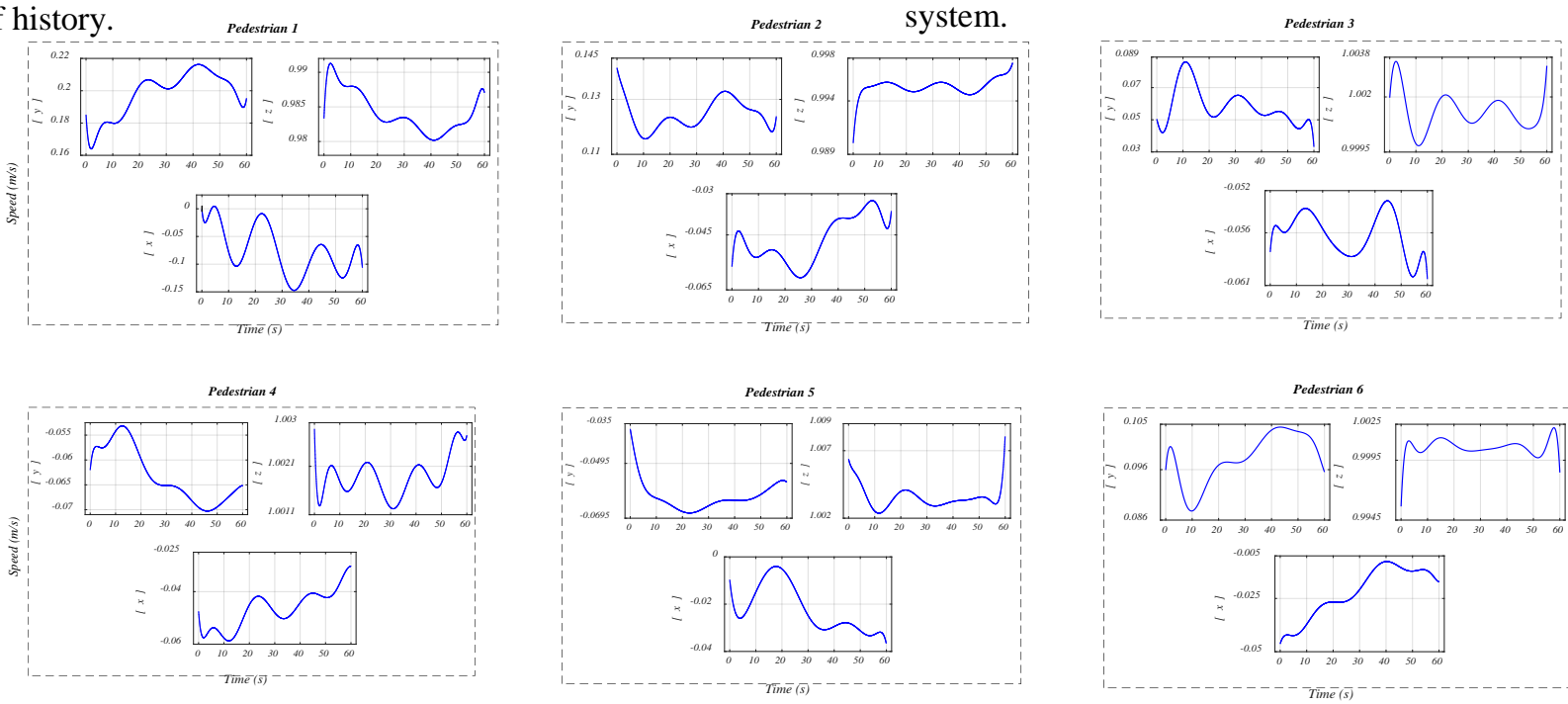

Fig. 9. Graphic representation of the Pedestrian center of gravity Speed simulation 
In Figure 10, is presented the simulation the response of the center of gravity of the movement of the pedestrian, it is noted that the acceleration is not constant on overing of time, therefore, in this work a study of this condition is made from each pedestrian, locating the instrument as indicated in [7].
The acceleration of the center of gravity depends to a great extent on the rigidity of the legs, which means that, at every moment, it is necessary to study the damping of the system, this parameter of said acceleration is determined as in [5], and it is represented in Figure 10.

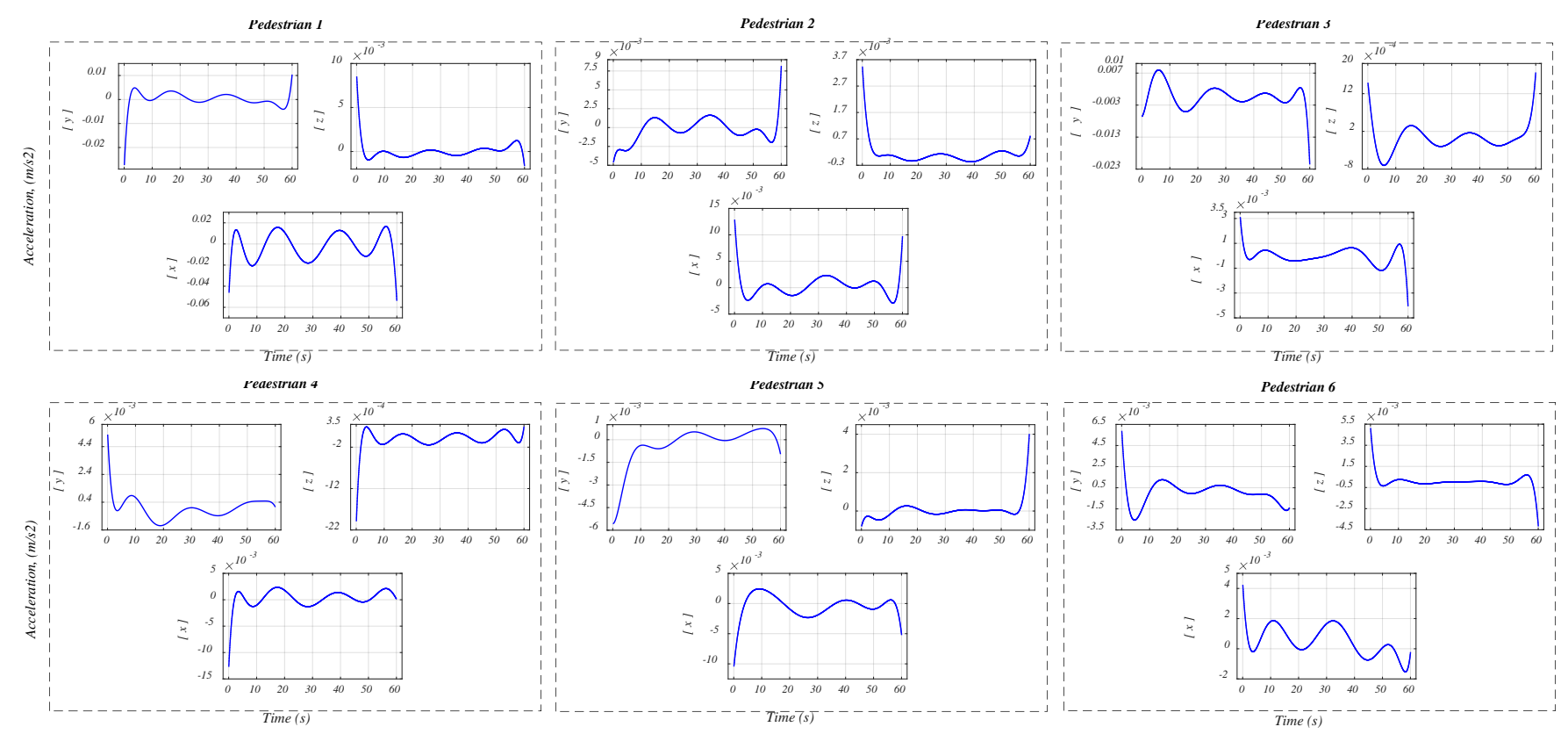

Fig. 10. Graphic representation of the Pedestrian center of gravity acceleration simulation results

In Figure 11, the energetic behavior in the center of gravity that the mass produces when walking the pedestrian is presented, it shows that the kinetic energy that the pedestrian contributes to the system is not constant over time, this condition studied in 60 seconds is determined with equation 14, using the data of the acceleration measurement of the mass and data those presented in Table 1.
The kinetic energy that contributes the center of gravity of the pedestrian depends to a great extent on the acceleration of its mass, for this reason, the system responds, generating potential energy. Applying equation 9 and 10, whit the movement equation is determined, where the elastic curve is found as a means of restoring the concrete footbridge.

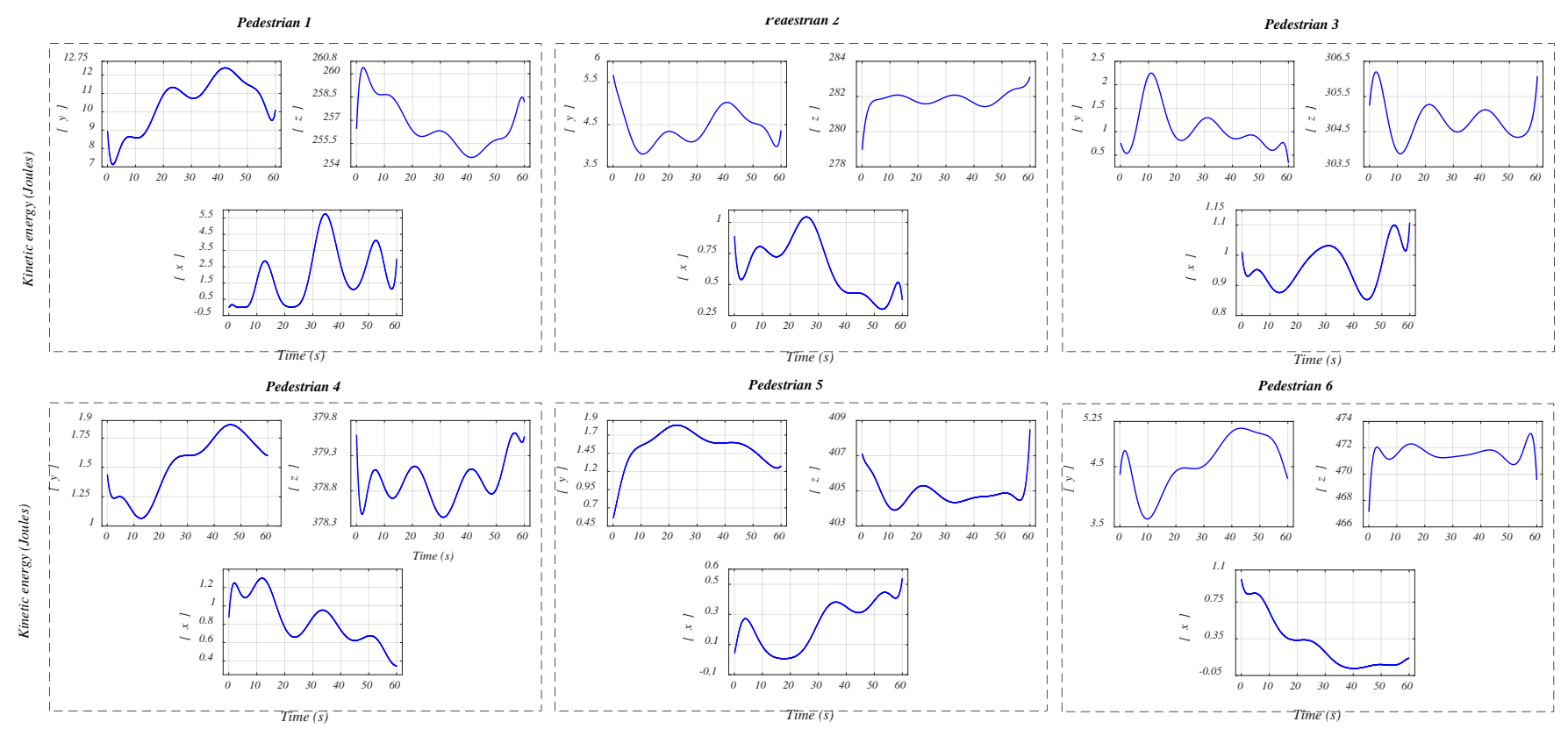

Fig. 11. Pedestrian center of gravity kinetic energy simulation results 
The evolution of displacements over time according to the energy contributed of pedestrian walking, are shown in Figure 12 , it is observed that the greatest magnitude occurs in the vertical. The presented simulation is achieved using the method of the three moments, where the highest bending moment is located and through the data of the slab mentioned in the energy analysis of this work, we can determine through the curve of the elastic, the displacements history in 60 seconds of time.
The potential energy determined with equations 16, 17 and 18 , and the kinetic energy supplied, are properly conservative in the system, since by equalize this two conditions we can determine the response of the footbridge damping, present in the elastic behavior. This development is dependent on the energy evolution of the mass and its acceleration, which generates the system elastic or plastic displacements as a measure of restoration of the concrete footbridge.
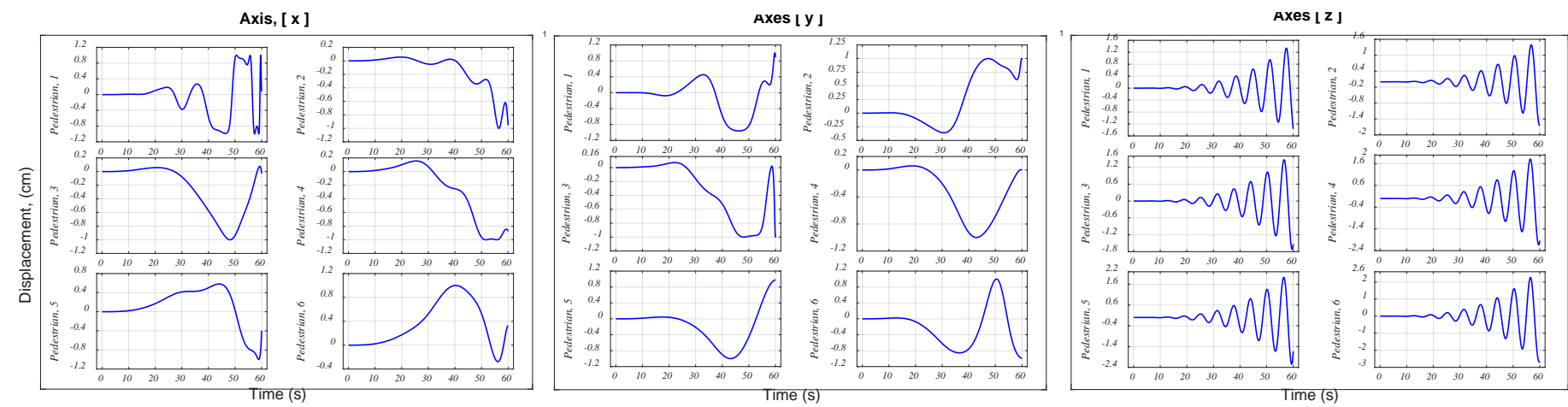

Fig. 12. Simulation of the result of the displacement on the walkway of the footbridge

\section{B. Study of the load patterns}

The accelerations observed in Figure 10, show acceptable magnitudes, since their behavior is similar with the values obtained in [27], where they are compared with the codes shown there, this indicates that the system remains in a state of adequate service, and does not present significant levels of instability, the authors refer that the codes future be will stricter [16], and that the designs comply with this regulations [13][14], the normative British National Annex Eurocode, SÉTRA, HIVOSS, AASHTO, LRDF in [6] refers to critical magnitudes, however, we recommend that according to the satisfactory results obtained, be compared and monitored in the future, with traffics different from the proposed, whose classification was focused on the type TC2, as used in [28], whose density ( $D=0.2$ pedestrians per square meter) is presented in the dynamic system block diagram.

The cyclic load patterns, determined from the equation of motion of the periodic load, were obtained as in [4], in addition, the numerical value of the dynamic load factor $\left(\alpha_{i}=\right.$ 0.371) [12][16], value that is determined, with the equation $F_{(t)}=$ $W_{p}+\sum_{i=1}^{n} W_{p} \alpha_{i} \operatorname{sen}\left(2 \pi i f_{p} t-\varphi_{i}\right)[13][15]$, whose data is shown in Figure 6, maintain a periodic sequence with respect to the stepby-step as found in [29], using $f_{p}=2.93 v_{p}-1.59 v_{p}^{2}+0.35 v_{p}^{3}$. [10] therefore, the numerical simulation of the periodic loading cycle with the values shown are very close to those presented by other authors.

The loading patterns determined from Newtonian mechanics and the data in Table 1, considering the measured acceleration readings, are presented in Figure 8, numerical values required to perform the presented simulation, with magnitudes very similar to those presented in [22], besides these values are very useful to compare them with the values obtained in Figure 6, where expected and very acceptable arguments are represented.
The displacements obtained from the periodic load are determined by applying the double integration method from the differential equation of the elastic EI $\frac{\partial^{2} y}{\partial x^{2}}=M$, incorporating the method of the three moments for bridges, to define the position of the major moment, it is assumed that the load that produces the maximum deflection is in the central part of the longest clearing, applying the method of superposition for beams the solution is given, as in [26], determining the magnitudes with the equation $\delta_{(t)}=\sum_{i=1}^{l} \frac{\left.F_{(t)}\right)^{3}}{48 E I}$, values that show the expected data, represented in graph 7; in the same way the displacements are obtained for the amount of movement generated by the mass, from the equation $\delta_{(t)}=\sum_{i=1}^{l} \frac{f_{(t)}{ }^{3}}{48 E I}$, where $\mathrm{f}_{(\mathrm{t})}$ determines the amount of movement from Newton's second law with the equation $f_{(t)}=m_{p} \alpha_{(t)}$, represented in graph 12 , both graphs show the satisfactory results of the present study. The results shown in graph 12 obtained from the conservation of energy with the coupling of the equation of motion with the mechanics of Lagrange, show values in the vertical, very close to those expected from graph 7 , the difference lies, in which there are magnitudes of acceleration with small differences, due to the damping that exists in the location of the instrument simulating the mass of the pedestrian, in addition, by the rigidity of the legs and by the damping in the model of walking.

\section{CONCLUSIONS}

In this research work was performed the measurement of the periodic load of the pedestrian walking on the surface of the footbridge, as well as the measurement of the movement of the mass concentrated in the center of gravity of the pedestrian, in both cases it was determined the displacement of the footbridge, applying the methodology of the double integration and the coupling of the equation of movement through Lagrange respectively. Obtaining results by implementing the methodology concludes with the following advantages: 
1. The model considers the history of the acceleration in the centroid of the mass, generating very approximate results of the total walking cycle of a pedestrian, reported by the authors, when the matrix coupling is individual.

2. The cyclic loading pattern in the centroid of the mass does not provide the total kinetic energy to determine the restoration displacements of the footbridge of the footbridge and depends on the potential energy of the system.

3. The matrix coupling of the motion equation when implemented determines the displacements generated by the potential energy of the system.

4. The analytical simulation of the energetic analysis shows results very approximated to those presented in the literature, besides, these are significant at the moment of evaluating them, because they are values from displacements in the cushioning

5. Based on the matrix coupling, through the mechanics of Lagrange, the methodology helped to identify the structural performance from starting the displacements found in the catwalk, which when compared from the literature show optimal service conditions in the study bridge.

\section{ACKNOWLEDGMENT}

The authors wish to express their gratitude to the Autonomous University of the State of Hidalgo for their financial support.

\section{REFERENCES}

[1] W. Shi, L. Wang, Z. Lu, and Q. Zhang, “Application of an artificial fish swarm algorithm in an optimum tuned mass damper design for a pedestrian bridge,” Appl. Sci., vol. 8, no. 2, 2018.

[2] T. Morbiato, R. Vitaliani, and A. Saetta, "Numerical analysis of a synchronization phenomenon: Pedestrian-structure interaction," Comput. Struct., vol. 89, no. 17-18, pp. 1649-1663, 2011.

[3] M. Cacho-Pérez, N. Frechilla, and A. Lorenzana, "Estimación de parámetros modales de estructuras civiles a partir de la función de respuesta en frecuencia,” Rev. Int. Metod. Numer. para Calc. y Disen. en Ing., vol. 33, no. 3-4, pp. 197-203, 2017.

[4] L. Gaile and I. Radinsh, "Footfall induced forces on stairs," 4th Int Sci. Conf. Civ. Eng. ’13, pp. 60-68, 1990.

[5] J. M. Franco, A. R. Ortiz, D. Gómez, and P. Thomson, "Evaluación de las vibraciones producidas por las personas en el puente peatonal del Club Noel en Cali, Colombia,” Proc. III Simp. Int. sobre diseño y construcción puentes Bucaramanga. Diciembre, vol. 2, p. 18

[6] A. Gheitasi, O. E. Ozbulut, S. Usmani, M. Alipour, and D. K. Harris, "Experimental and analytical vibration serviceability assessment of an in-service footbridge,” Case Stud. Nondestruct. Test. Eval., vol. 6, pp. 79-88, 2016.

[7] H. V. Dang and S. Živanović, "Experimental characterisation of walking locomotion on rigid level surfaces using motion capture system,” Eng. Struct., vol. 91, pp. 141-154, 2015.

[8] S. L. James, "Biomechanics of running and sprinting.pdf,” no. 2, pp. 1-12, 2015

[9] E. T. Ingólfsson, C. T. Georgakis, and J. Jönsson, "Pedestrianinduced lateral vibrations of footbridges: A literature review,” Eng.
Struct, vol. 45, pp. 21-52, 2012

[10] F. Venuti, V. Racic, and A. Corbetta, "Modelling framework for dynamic interaction between multiple pedestrians and vertical vibrations of footbridges,” J. Sound Vib., vol. 379, pp. 245-263, 2016.

[11] W. Dargie, "Analysis of time and frequency domain features of accelerometer measurements,” Proc. - Int. Conf. Comput. Commun. Networks, ICCCN, no. 1, pp. 3-8, 2009.

[12] A. M. Avossa, C. Demartino, and F. Ricciardelli, "Probability distribution of footbridge peak acceleration to single and multiple crossing walkers,” Procedia Eng., vol. 199, pp. 2766-2771, 2017.

[13] C. C. Caprani and E. Ahmadi, "Formulation of human-structure interaction system models for vertical vibration,” J. Sound Vib., vol. 377, pp. 346-367, 2016

[14] Hivoss, "Human induced Vibrations of Steel Structures Design of Footbridges,” Response, 2007.

[15] J. De Sebastián, I. M. Díaz, C. M. Casado, A. V. Poncela, and A Lorenzana, "Evaluación de la predicción de aceleraciones debidas al tránsito peatonal en una pasarela en servicio,” Inf. la Construcción, vol. 65, no. 531, pp. 335-348, 2013.

[16] V. Racic, A. Pavic, and J. M. W. Brownjohn, "Experimental identification and analytical modelling of human walking forces: Literature review,” J. Sound Vib., vol. 326, no. 1-2, pp. 1-49, 2009.

[17] J. Guilherme and J. Maurício, "Dynamic analysis of pedestrian footbridges based on probabilistic modelling,” no. July, pp. 13311336, 2014

[18] S. Živanović, A. Pavić, and P. Reynolds, "Probability-based prediction of multi-mode vibration response to walking excitation," Eng. Struct., vol. 29, no. 6, pp. 942-954, 2007.

[19] G. Pernica, "Dynamic Load Factors for Pedestrian Movements and Rhythmic Exercises,” Can. Acoust., vol. 18, no. 2, pp. 3-18, 1990.

[20] C. C. Caprani, "Application of the pseudo-excitation method to assessment of walking variability on footbridge vibration," Comput. Struct., vol. 132, pp. 43-54, 2014.

[21] S. Živanović, A. Pavic, and P. Reynolds, Vibration serviceability of footbridges under human-induced excitation: A literature review, vol. 279, no. 1-2. 2005

[22] M. Cacho-Pérez and A. Lorenzana, "Modelo mecánico acoplado para la simulación 2D del tránsito peatonal por estructuras esbeltas,” Rev. Int. Metod. Numer. para Calc. y Disen. en Ing., vol. 33, no. 1-2, pp. 90-96, 2017.

[23] K. Van Nimmen, G. Lombaert, G. De Roeck, and P. Van den Broeck, "The impact of vertical human-structure interaction on the response of footbridges to pedestrian excitation,” J. Sound Vib., vol. 402, pp. 104-121, 2017.

[24] E. Shahabpoor, A. Pavic, V. Racic, and S. Zivanovic, "Effect of group walking traffic on dynamic properties of pedestrian structures,” J. Sound Vib., vol. 387, pp. 207-225, 2017.

[25] E. Shahabpoor, A. Pavic, and V. Racic, "Identification of massspring-damper model of walking humans," Structures, vol. 5, pp. 233-246, 2016

[26] J. S. V. Reyes, "Método algebráico para determinar la deformación por deflexión en vigas estáticamente indeterminadas,” pp. 1-6, 2007.

[27] R. Salgado, J. M. Branco, P. J. S. Cruz, and G. Ayala, "Serviceability assessment of the Góis footbridge using vibration monitoring," Case Stud. Nondestruct. Test. Eval., vol. 2, no. 1, pp. 71-76, 2014.

[28] E. Lai, C. Gentile, and M. G. Mulas, "Experimental and numerical serviceability assessment of a steel suspension footbridge,” J. Constr. Steel Res., vol. 132, pp. 16-28, 2017.

[29] E. Shahabpoor, A. Pavic, and V. Racic, "Structural vibration serviceability: New design framework featuring human-structure interaction,” Eng. Struct., vol. 136, pp. 295-311, 2017. 